\title{
Paracrine SDF-1a signaling mediates the effects of PSCs on GEM chemoresistance through an IL-6 autocrine loop in pancreatic cancer cells
}

\author{
Hui Zhang ${ }^{1, *}$, Huanwen Wu ${ }^{1, *}$, Jian Guan ${ }^{2}$, Li Wang ${ }^{1}$, Xinyu Ren ${ }^{1}$, Xiaohua Shi ${ }^{1}$, \\ Zhiyong Liang ${ }^{1}$ and Tonghua Liu ${ }^{1}$ \\ ${ }^{1}$ Department of Pathology, Peking Union Medical College Hospital, Chinese Academy of Medical Science, Beijing, PR China \\ 2 Department of Pathology, Cancer Institute and Hospital, Chinese Academy of Medical Sciences, Beijing, PR China \\ * These authors contributed equally to this work \\ Correspondence to: Tonghua Liu, email: liuth_pumch192911@yahoo.com
}

Zhiyong Liang, email: liangzhiyong1220@yahoo.com

Keywords: Pancreatic cancer, Pancreatic stellate cells, Chemoresistance, SDF-1a, IL-6

Received: November 23, $2014 \quad$ Accepted: December 25, $2014 \quad$ Published: December 30, 2014

This is an open-access article distributed under the terms of the Creative Commons Attribution License, which permits unrestricted use, distribution, and reproduction in any medium, provided the original author and source are credited.

\section{ABSTRACT}

Pancreatic cancer exhibits the poorest prognosis among all tumors and is characterized by high resistance to the currently available chemotherapeutic agents. Our previous studies have suggested that stromal components could promote the chemoresistance of pancreatic cancer cells (PCCs). Here, we explored the roles of pancreatic stellate cells (PSCs) and the SDF-1a/CXCR4 axis in pancreatic cancer chemoresitance. Our results showed that primary PSCs typically expressed SDF1a, whereas its receptor CXCR4 was highly expressed in PCCs. PSC-conditioned medium (PSC-CM) inhibited Gemcitabine (GEM)-induced cytotoxicity and apoptosis in the human PCC line Panc-1, which was antagonized by an SDF-1a neutralizing Ab. Recombinant human SDF-1a (rhSDF-1a) increased IL-6 expression and secretion in Panc-1 cells in a time and dose-dependent manner, and this effect was suppressed by the CXCR4 antagonist AMD3100. rhSDF-1a protected Panc-1 cells from GEM-induced apoptosis, and the protective effect was significantly reduced by blocking IL-6 using a neutralizing antibody. Moreover, rhSDF-1a increased FAK, ERK1/2, AKT and P38 phosphorylation in Panc-1 cells, and either FAK or ERK1/2 inhibition suppressed SDF-1a-upregulated IL-6 expression. SDF-1a-induced AKT activation was almost completely blocked by FAK inhibition. In conclusion, we demonstrate for the first time that PSCs promote the chemoresistance of PCCs to GEM, and this effect is mediated by paracrine SDF-1a/CXCR4 signaling-induced activation of the intracellular FAK-AKT and ERK1/ 2 signaling pathways and a subsequent IL- 6 autocrine loop in PCCs. Our findings indicate that blocking the PSC-PCC interaction by inhibiting SDF-1a/CXCR4 signaling may be a promising therapeutic strategy for overcoming chemoresistance in pancreatic cancer.

\section{INTRODUCTION}

Pancreatic cancer is a highly lethal malignancy with occult symptoms, rapid development, early metastasis and high resistance to chemotherapy $[1,2]$. At the time of diagnosis, the tumor is confined to the pancreas in only approximately $10 \%$ of patients. The majority of patients have locally advanced tumors and/or unresectable distant metastases [3]. Therefore traditional chemotherapy is indispensable in the current treatment of pancreatic cancer. However, even the most effective first-line chemotherapeutic agent, gemcitabine (GEM), can only achieve a slight improvement in survival. Moreover, numerous clinical studies have shown that the combination of GEM with other cytotoxic drugs is unlikely to significantly improve the prognosis of 
pancreatic cancer. Therefore, there is an urgent need to develop novel therapeutic strategies to effectively treat this devastating carcinoma $[4,5]$.

Pancreatic stellate cells (PSCs) are a crucial component in the tumor microenvironment of pancreatic cancer [6]. PSCs remain in a quiescent state in normal pancreas, however, they can transition to a myofibroblastlike phenotype under various pathological conditions, including cancer and inflammatory disease. Activated PSCs are able to proliferate, migrate, and synthesize various cytokines and extracellular matrix components, resulting in extensive proliferation of fibrous connective tissue (desmoplasia), one of the most characteristic histopathological changes in pancreatic cancer [7-9]. In recent years, researchers have increasingly recognized the critical role of the interaction between PSCs and pancreatic cancer cells (PCCs) in pancreatic cancer pathobiology. Tumor cells secrete extracellular factors to activate PSCs, and in turn, PSCs release a large number of cytokines and extracellular matrix proteins, regulating tumor cell proliferation, apoptosis, invasion, metastasis, and drug resistance [8-10]. Our recent studies have also revealed that PSCs and the stromal microenvironment play a critical role in pancreatic cancer development and chemoresistance and indicated that blocking the stromatumor cell interaction may be a promising therapeutic strategy for overcoming chemoresistance in pancreatic cancer $[11,12]$.

Stromal cell-derived factor-1 (SDF-1), also named CXCL12 (chemokine (C-X-C motif) ligand 12)), is a member of the CXC chemokine family of proinflammatory mediators. SDF-1 exerts its biological effect by binding and activating the $\mathrm{CXC}$ chemokine receptor 4 (CXCR4), a $\mathrm{G}$ protein-coupled receptor, which is the predominant receptor for SDF-1 and is frequently overexpressed in a variety of human cancer cells. As the predominant isoform of SDF-1, SDF-1 $\alpha$ is expressed in many organs $[13,14]$. In recent years, it has become apparent that the SDF-1 $\alpha / \mathrm{CXCR} 4$ biological axis is a critical mediator of tumor-stromal interactions and is closely related to the malignant process and poor prognosis in a variety of epithelial cancers, such as pancreatic cancer, liver cancer, lung cancer, breast cancer, and prostate cancer [15-19]. Although preliminary data have indicated that the SDF-1/CXCR4 axis might induce chemoresistance in PCCs, its underlying mechanism remains largely unknown. In addition, it is unclear whether and how the SDF-1/CXCR4 axis mediates PSC-induced chemoresistance in pancreatic cancer.

In the present study, we investigated the roles and mechanisms of PSCs and the SDF-1 $\alpha / \mathrm{CXCR} 4$ biological axis in GEM chemoresistance in pancreatic cancer. Our study aimed to further clarify the mechanism of chemoresistance in a tumor microenvironmentdependent model and identify novel therapeutic targets for overcoming chemoresistance in pancreatic cancer.

\section{RESULTS}

\section{SDF-1 $\alpha$ and CXCR4 expression in PSCs and PCCs}

Activated primary PSCs isolated from pancreatic cancer tissues were verified by immunofluorescence staining for $\alpha$-SMA and vimentin (Figure 1a). We evaluated the mRNA expression level of SDF- $1 \alpha$ and CXCR4 in four PCC lines (MIA PaCa-2, Panc-1, AsPC1, BxPC-3) and four primary PSCs (PSC-S1, PSC-S2, PSC-S3, PSC-S4) by RT-qPCR. SDF-1 $\alpha$ mRNA expression in the four PSCs was significantly higher than that in Panc-1, MIA PaCa-2 and BxPC-3 cells. Among the four PSCs, PSC-S1 showed a relatively lower level of SDF-1 $\alpha$ mRNA expression (Figure 1b). In contrast with SDF-1 $\alpha$, CXCR4 mRNA expression in the four PSCs was significantly lower than that in Panc-1 and AsPC1 cells (Figure 1c). Because of the expression pattern, Panc-1 cells (low SDF-1 $\alpha$ expression and high CXCR4 expression) were used for the subsequent experiments on the PSC-PCC interaction.

We also investigated a-SMA, SDF-1 $\alpha$ and CXCR4 protein expression in the four resected specimens used for PSCs isolation by immunohistochemistry (Figure 1d-1f). Activation of the PSCs in the pancreatic cancer tissues was confirmed by the expression of a-SMA. In all four cases, the PCCs demonstrated moderate to strong CXCR4 staining and weak SDF-1 $\alpha$ staining, while PSCs in three cases (PSC-S2, PSC-S3, PSC-S4) showed moderate to strong SDF- $1 \alpha$ staining and negative CXCR4 staining. However, PSC-S1 was negative for both SDF- $1 \alpha$ and CXCR4 staining. Given the relatively low expression level of SDF- $1 \alpha$ in PSC-S1, we used the other three PSCs to harvest PSC-CM for further investigation.

We also found that distant samples of normal pancreas tissue in all cases showed negative staining for a-SMA, SDF-1 $\alpha$ and CXCR4 (except islet cells) (Figure 1g-1i). To further confirm whether the high SDF$1 \alpha$ expression was due to PSCs activation in pancreatic cancer, we induced activated PSCs to enter a relatively quiescent state by treating the cells with all-trans retinoic acid (ATRA). ATRA is an active metabolite of vitamin A. Our previous studies showed that ATRA could prevent the activation of PSCs by decreasing cell proliferation, a-SMA expression and collagen production [12]. After treatment with ATRA, the PSCs showed morphological changes and contained fat droplets, similar to quiescent PSCs (data not shown). We found that the levels of SDF-1 $\alpha$ mRNA and protein in PSCs were significantly decreased after ATRA treatment (Figure $1 \mathrm{j}$ and $1 \mathrm{k}$ ). 


\section{SDF-1 $\alpha$ mediated the effects of PSCs on GEM- induced cytotoxicity in Panc-1 cells}

To clarify whether PSCs can mediate the chemoresistance of PCCs, Panc-1 cells were treated with GEM in the presence of various doses of PSC-CM. The MTT assay showed that PSC-conditioned medium (PSCCM) inhibited GEM-induced cytotoxicity in Panc-1 cells in a dose-dependent manner (Figure 2a and 2b). High doses of PSC-CM ( $40 \%$ or more) significantly decreased GEM-induced cytotoxicity in Panc-1 cells $(\mathrm{P}<0.05)$. The Panc-1 cell viability reached a peak when the cells were co-cultured with $80 \%$ PSC-CM, although no significant difference was found between Panc-1 cells co-cultured with $80 \%$ and $100 \%$ PSC-CM.

Subsequently, Panc- 1 cells were cultured in serumfree medium containing $80 \%$ PSC-CM and then treated with GEM in the absence or presence of an SDF-1 $\alpha$ neutralizing Ab for $24 \mathrm{~h}, 48 \mathrm{~h}$, or $72 \mathrm{~h}$. The MTT assay

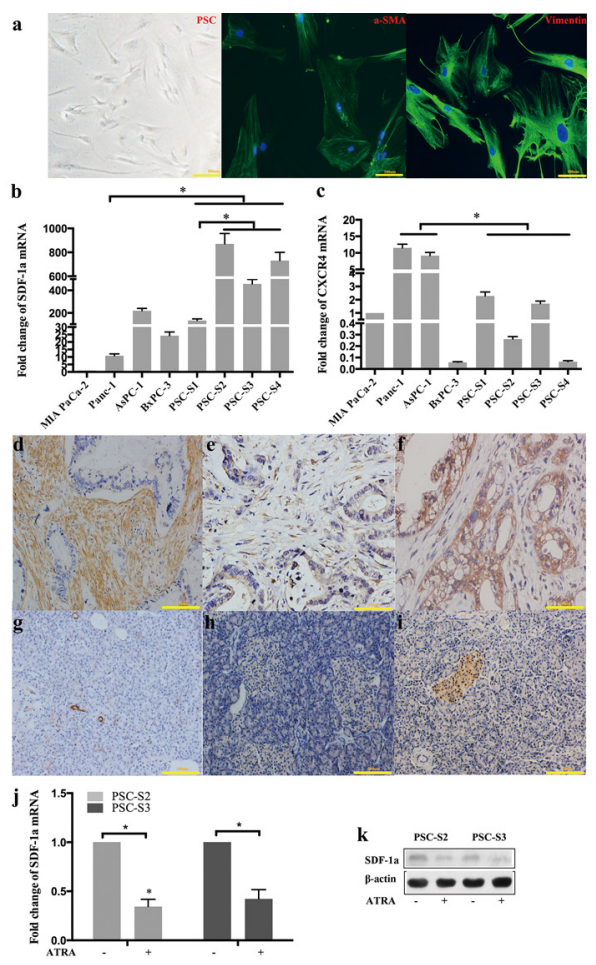

Figure 1: SDF-1 $\alpha$ and CXCR4 expression in PSCs and PCCs. Activated primary PSCs isolated from pancreatic cancer tissues were verified by immunofluorescence staining for $\alpha$-SMA and vimentin (a); SDF-1a mRNA (b) and CXCR4 (c) mRNA expression was examined by RT-qPCR. The expression of the target mRNA was normalized to that of $\beta$-actin mRNA. The values are expressed relative to 1.00 for expression in MIA $\mathrm{PaCa}-2$ cells. The bars represent the mean of three independent experiments $\pm \mathrm{SE} . *, \mathrm{P}<0.05$. In the four resected pancreatic cancer samples used for PSC isolation, $\alpha$-SMA, SDF- $1 \alpha$ and CXCR4 were detected by immunohistochemistry in pancreatic cancer tissues (d, e and f) and distant normal pancreatic tissues ( $g, h$ and i). Two primary PSCs were harvested and analyzed for SDF-1 $\alpha$ expression by RT-qPCR (j) and Western blot (k). demonstrated that the protective effect of PSCs on GEMinduced cytotoxicity was significantly antagonized by specific inhibition of SDF-1a in a time-dependent manner (Figure 2b).

\section{SDF-1 $\alpha$ mediated the effects of PSCs on GEM- induced apoptosis in Panc-1 cells}

Apoptosis is considered to be the major mechanism of GEM-induced cell death [11]. To further explore the roles of PSCs and SDF- $1 \alpha$ in the chemoresistance of Panc1 cells, the effects of PSC-CM and SDF- $1 \alpha$ neutralizing $\mathrm{Ab}$ on GEM-induced apoptosis in Panc-1 cells were assessed by Hoechst staining and Annexin V/PI flow cytometry analysis.

Hoechst staining indicated that the number of GEMinduced apoptotic Panc-1 cells was significantly decreased by PSC-CM, which was demonstrated by an decreased proportion of condensed nuclei $(\mathrm{P}<0.05)$ (Figure 3a and $3 b$ ). Moreover, specific inhibition of SDF- $1 \alpha$ by a neutralizing $\mathrm{Ab}$ antagonized the protective effect of PSC$\mathrm{CM}$ on GEM-induced apoptosis in Panc-1 cells $(\mathrm{P}<0.05)$. Similar results were observed with Annexin V/PI analysis (Figure $3 \mathrm{c}$ and $3 \mathrm{~d}$ ). PSC-CM significantly decreased the early apoptosis rate induced by GEM from $23 \%$ to $8.6 \%$ $(\mathrm{P}<0.05)$, which was at least partially blocked by specific inhibition of SDF-1 $\alpha(\mathrm{P}<0.05)$. Collectively, these findings suggested that SDF- $1 \alpha$ at least partially mediated the
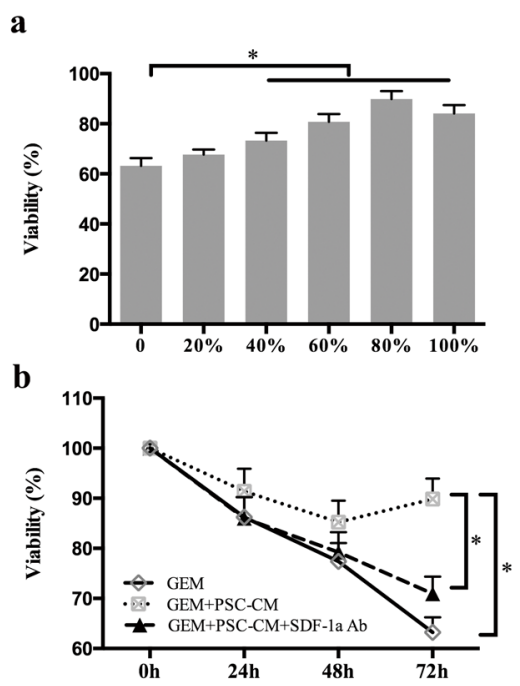

Figure 2: PSC-CM suppressed GEM-induced cytotoxicity in Panc-1 cells. (a): Panc-1 cells were treated with GEM $(10 \mu \mathrm{M})$ in the presence of various doses of PSC$\mathrm{CM}$. Cancer cell viability was examined $72 \mathrm{~h}$ post-treatment using the MTT assay. (b): Panc-1 cells were treated with GEM $(10 \mu \mathrm{M})$ with or without PSC-CM $(80 \%)$ and SDF-1a Ab (100 $\mathrm{ng} / \mathrm{ml})$. After $24 \mathrm{~h}, 48 \mathrm{~h}$, or $72 \mathrm{~h}$ of treatment, cell growth was determined using MTT. Bars represent the mean of three independent experiments \pm SE.*, $\mathrm{P}<0.05$. 
effects of PSC on GEM-induced apoptosis in Panc-1 cells.

\section{The SDF-1 $\alpha / C X C R 4$ axis upregulated IL-6 expression in Panc-1 cells}

As a chemotactic factor, SDF-1 $\alpha$ has been reported to stimulate endothelial cells, fibroblasts and tumor cells to secrete a variety of factors, such as IL-6, IL-8, and matrix metalloproteinases (MMP). We further explored the effects of SDF- $1 \alpha$ on IL- 6 and IL- 8 expression in Panc- 1 cells.

Panc- 1 cells were treated with rhSDF-1 $\alpha$ (100 ng/ $\mathrm{ml}$ ) for $0 \mathrm{~h}, 24 \mathrm{~h}, 48 \mathrm{~h}, 72 \mathrm{~h}$ and harvested for RT-qPCR. The mRNA levels of both IL-6 and IL-8 were increased significantly $(P<0.05)$ (Figure $4 \mathrm{a}$ and $4 \mathrm{~b})$. However, compared with IL-8, the IL-6 mRNA level was more significantly altered and showed a time-dependent pattern with a peak at $72 \mathrm{~h}$. To further test whether rhSDF-1 $\alpha$ induced IL-6 expression in a dose-dependent manner, Panc-1 cells were treated with different concentrations of rhSDF- $1 \alpha$ as indicated in Figure 4c and 4d, and the IL-6 expression and secretion levels were detected by RT-qPCR and ELISA, respectively. Our results revealed that rhSDF$1 \alpha$ increased IL- 6 expression and secretion in Panc- 1 cells in both a time-dependent and a dose-dependent manner, with a peak value in cells treated with $100 \mathrm{ng} / \mathrm{ml} \mathrm{rhSDF}$ $1 \alpha$ for $72 \mathrm{~h}$.

In recent years, it has been reported that SDF- $1 \alpha$ can also exert its biological effect by binding to another CXC chemokine receptor, CXCR7. Moreover, gene regulation via SDF-1 $\alpha / \mathrm{CXCR} 4$ and SDF- $1 \alpha / \mathrm{CXCR} 7$ may be completely different [21]. Therefore, we confirmed whether the upregulation of IL- 6 by SDF-1 $\alpha$ in Panc- 1 cells was mediated by CXCR4. Our results showed that the SDF-1 $\alpha$-induced upregulation of IL- 6 expression was significantly suppressed by the CXCR4 antagonist, AMD3100 (Figure 4e and 4f).

\section{The enhancing effects of SDF-1 $\alpha$ on GEM chemoresistance in Panc-1 cells were mediated by IL-6}

Previous studies have shown that the serum levels of IL-6 were elevated and negatively correlated with the therapeutic effects of GEM in patients with pancreatic cancer [22]. As described above, we verified that SDF- $1 \alpha$ mediated the effects of PSC-CM on GEM chemoresistance, and exogenous SDF-1 $\alpha$ led to the upregulation of IL- 6 expression in Panc- 1 cells. Therefore,

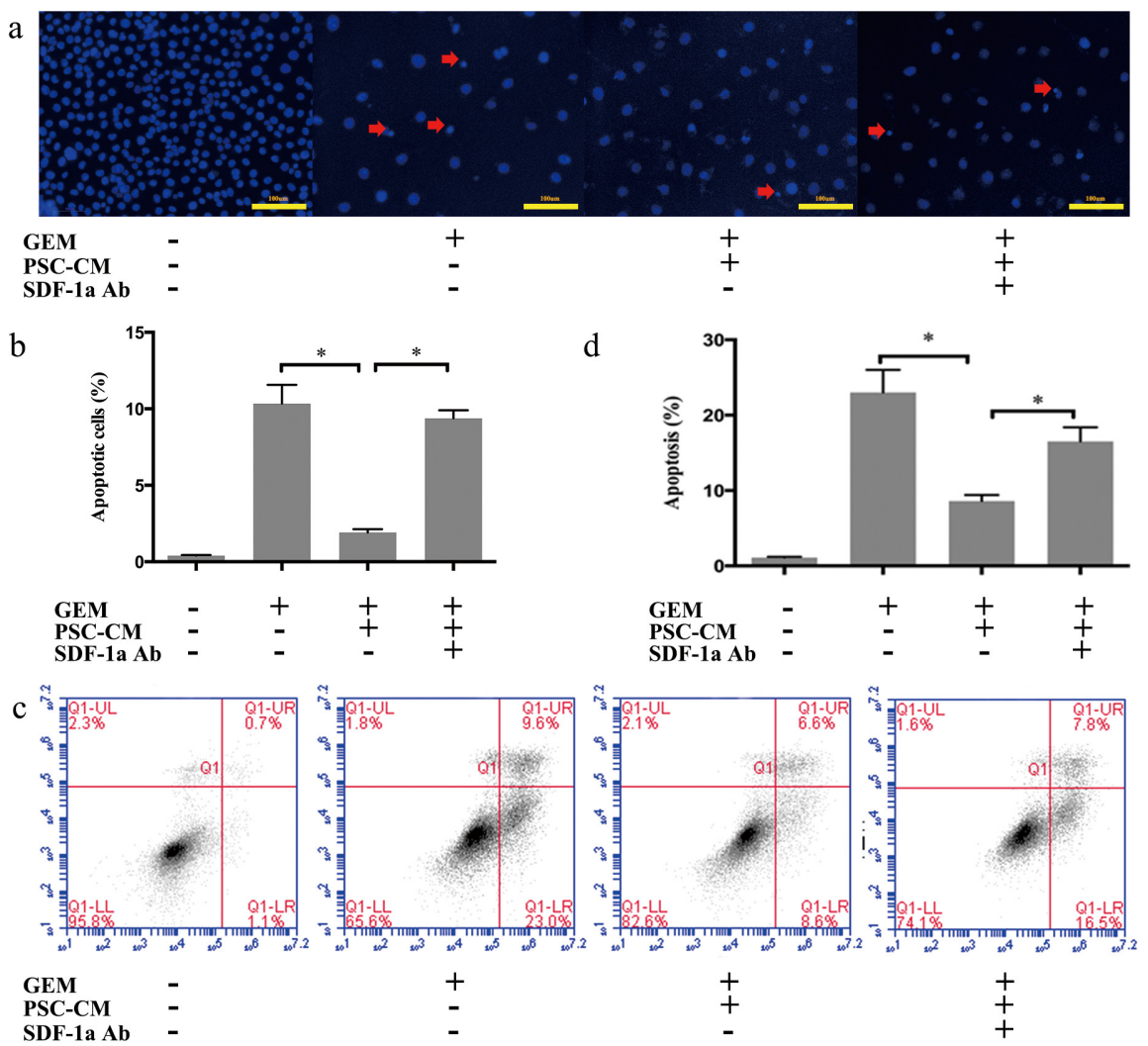

Figure 3: SDF-1 $\alpha$ mediated the effects of PSC-CM on GEM-induced apoptosis in Panc-1 cells. Panc-1 cells were treated with GEM $(10 \mu \mathrm{M})$ with or without PSC-CM (80\%) and SDF-1 $\alpha$ Ab $(100 \mathrm{ng} / \mathrm{ml})$ for $72 \mathrm{~h}$. (a): Apoptotic cells were examined by Hoechst 33342 staining (the arrow indicates the apoptotic cells), and (b) the percentage of apoptotic cells statistically analyzed. (c): Cells were harvested for flow cytometry analysis of Annexin-V/PI labeling, and (d) the proportion of cells in early-stage apoptosis was statistically analyzed. Bars represent the mean of three independent experiments \pm SE. *, $\mathrm{P}<0.05$. 
we further explored the influence of IL-6 on GEM-induced apoptosis in Panc-1 cells. Our results showed that the protective effect of rhSDF-1 $\alpha$ on GEM-induced apoptosis was significantly inhibited by the specific inhibition of IL-6 using a neutralizing antibody $(\mathrm{P}<0.05)$ (Figure 5a$5 d)$.

\section{SDF-1a upregulated IL-6 expression in Panc- 1 cells through activation of the FAK-AKT and ERK1/2 signaling pathways}

To further clarify the mechanism underlying the upregulation IL- 6 by SDF-1 $\alpha$, we detected the expression and phosphorylation of FAK, AKT, ERK1/2 and P38 in Panc-1 cells by Western blot. Our results indicated that the levels of FAK, AKT ERK1/2 and P38 phosphorylation in Panc- 1 cells were all significantly elevated after $30 \mathrm{~min}$ of $\operatorname{rhSDF}-1 \alpha$ treatment, and the effects lasted for $4 \mathrm{~h}$. The levels of protein expression were not significantly affected (Figure 6a).

Both AKT and ERK1/2 are key kinases that act downstream of FAK. Our previous study demonstrated that the FAK/AKT signaling pathway is involved in pancreatic cancer chemoresistance [11]. Therefore, we further explored whether FAK functioned upstream of the AKT or ERK1/2 signaling pathways. The effect of SDF-1 $\alpha$
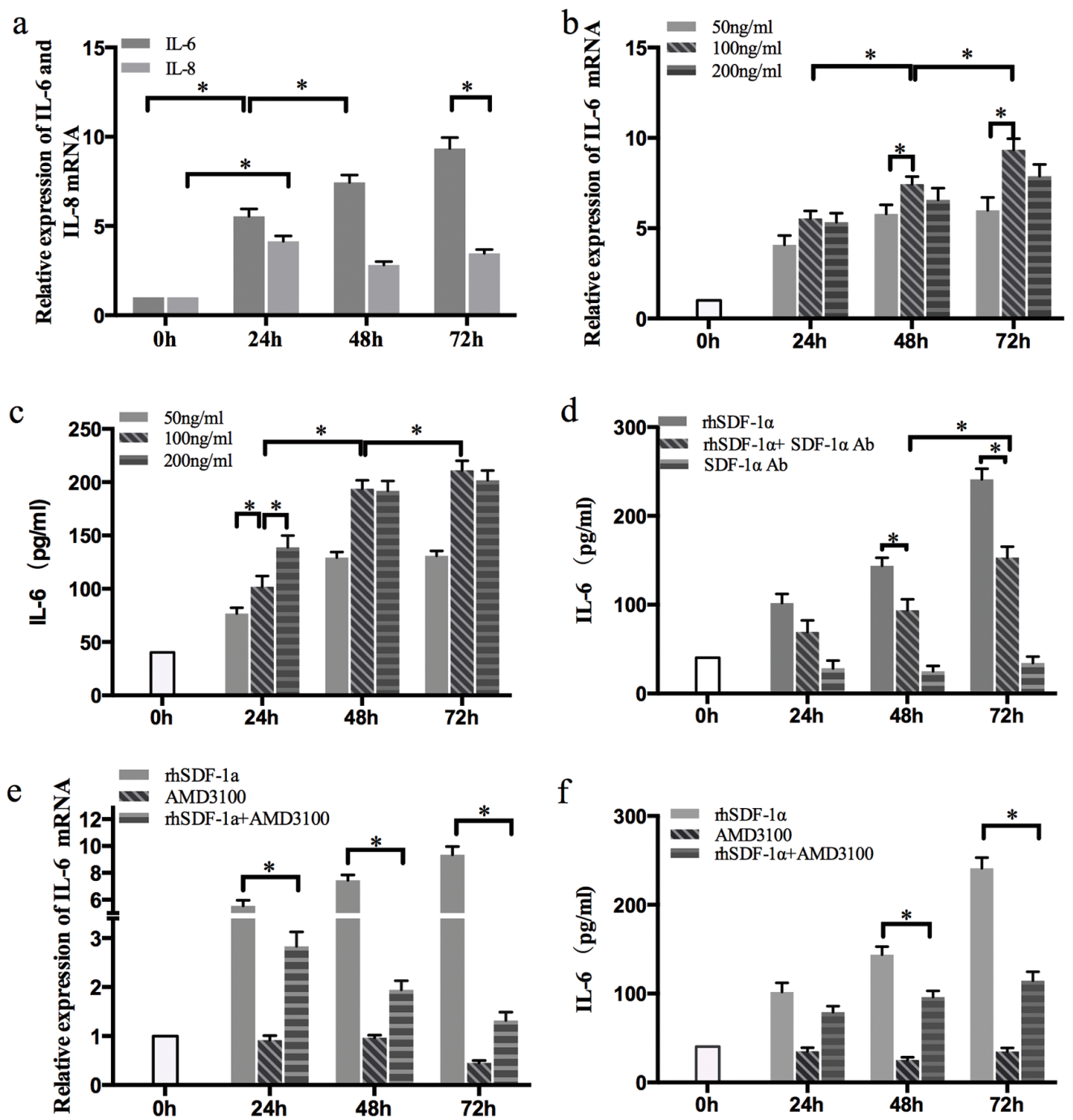

Figure 4: The effects of SDF-1 $\alpha$ on GEM chemoresistance in Panc-1 cells were mediated by IL-6. (a): Panc-1 cells were treated with rhSDF-1 $\alpha$ protein $(100 \mathrm{ng} / \mathrm{ml})$ or control vehicle, cultured for $24 \mathrm{~h}, 48 \mathrm{~h}$, or $72 \mathrm{~h}$ and harvested for RT-qPCR of IL-6 and IL-8. (b): Cells were treated with various concentrations of rhSDF-1a for $24 \mathrm{~h}, 48 \mathrm{~h}$, or $72 \mathrm{~h}$, and IL-6 mRNA was examined by RT-qPCR. (c): Cells were treated with various concentration of SDF-1 $\alpha$ for 24 h, 48 h, or 72 h. IL-6 protein was examined by ELISA. (d): Cells were treated with rhSDF-1 $\alpha(100 \mathrm{ng} / \mathrm{ml})$ and/or SDF- $1 \alpha \mathrm{Ab}(100 \mathrm{ng} / \mathrm{ml})$ for $24 \mathrm{~h}, 48 \mathrm{~h}$, or $72 \mathrm{~h}$, and IL-6 protein was examined by ELISA. Panc-1 cells were pretreated with the CXCR4 receptor antagonist AMD3100 or the vehicle for 6 hours. Cells were treated with rhSDF-1 $\alpha$ (100 ng/ $\mathrm{ml}$ ) or the vehicle for an additional $24 \mathrm{~h}, 48 \mathrm{~h}$, of $72 \mathrm{~h}$. The cells and supernatants were collected for analysis of IL-6 by RT-qPCR (e) and ELISA (f), respectively. The bars represent the mean of three independent experiments $\pm \mathrm{SE} . *, \mathrm{P}<0.05$. 
on AKT activation in Panc-1 cells was almost completely blocked by specific inhibition of FAK phosphorylation using the small molecule inhibitor PF573228. However, SDF- $1 \alpha$-induced ERK1/2 phosphorylation in Panc- 1 cells was not affected by FAK inhibition (Figure $6 b$ ).

To determine whether SDF- $1 \alpha$-induced FAK/ AKT, ERK1/2 and P38 activation was involved in IL-6 upregulation in Panc-1 cells, small molecule inhibitors of FAK (PF573228), ERK1/2 (PD98059) and P38 (SB20938) were used. The effects of these inhibitors on their corresponding kinase activity were verified by western blot (Figure 6b-6c). SDF-1 $\alpha$-induced upregulation of IL-6 mRNA and protein expression was partially antagonized by both FAK/AKT inhibition and ERK1/2 inhibition $(\mathrm{P}<0.05)$ in a time-dependent manner (Figure 6e and 6f), while specific inhibition of $\mathrm{P} 38$ activation did not affect the upregulation of IL- 6 expression induced by SDF- $1 \alpha$.

These results confirmed that SDF- $1 \alpha$ upregulates IL-6 expression through the activation of the FAK-AKT and ERK1/2 signaling pathways, and not the P38 signaling pathway, in Panc-1 cells.

\section{DISCUSSION}

A high resistance to chemotherapy and prominent desmoplastic stroma are two main contributing factors to the poor outcome of pancreatic cancer. Our group and others have increasingly recognized the critical role of tumor stroma in pancreatic cancer chemoresistance $[11,23,24]$. PSCs are a critical cellular component of pancreatic cancer stroma. In pancreatic cancer, PSCs transition from a quiescent phase to an activated phase in which they proliferate, migrate, and secrete excessive amounts of soluble factors and extracellular matrix (ECM) proteins, leading to fibrosis of the pancreas. Activated PSCs may regulate PCCs growth, survival, metastasis, and chemoresistance $[8,9,25]$. However, the mechanism of chemoresistance mediated by PSCs in pancreatic cancer is not well defined.

SDF- $1 \alpha$ and its specific receptor CXCR4 are highly expressed in a variety of tumors, including gastric, colorectal, breast, and ovarian cancers [26-29]. Our in vivo and in vitro results demonstrated that activated primary PSC from pancreatic cancer tissues typically expressed

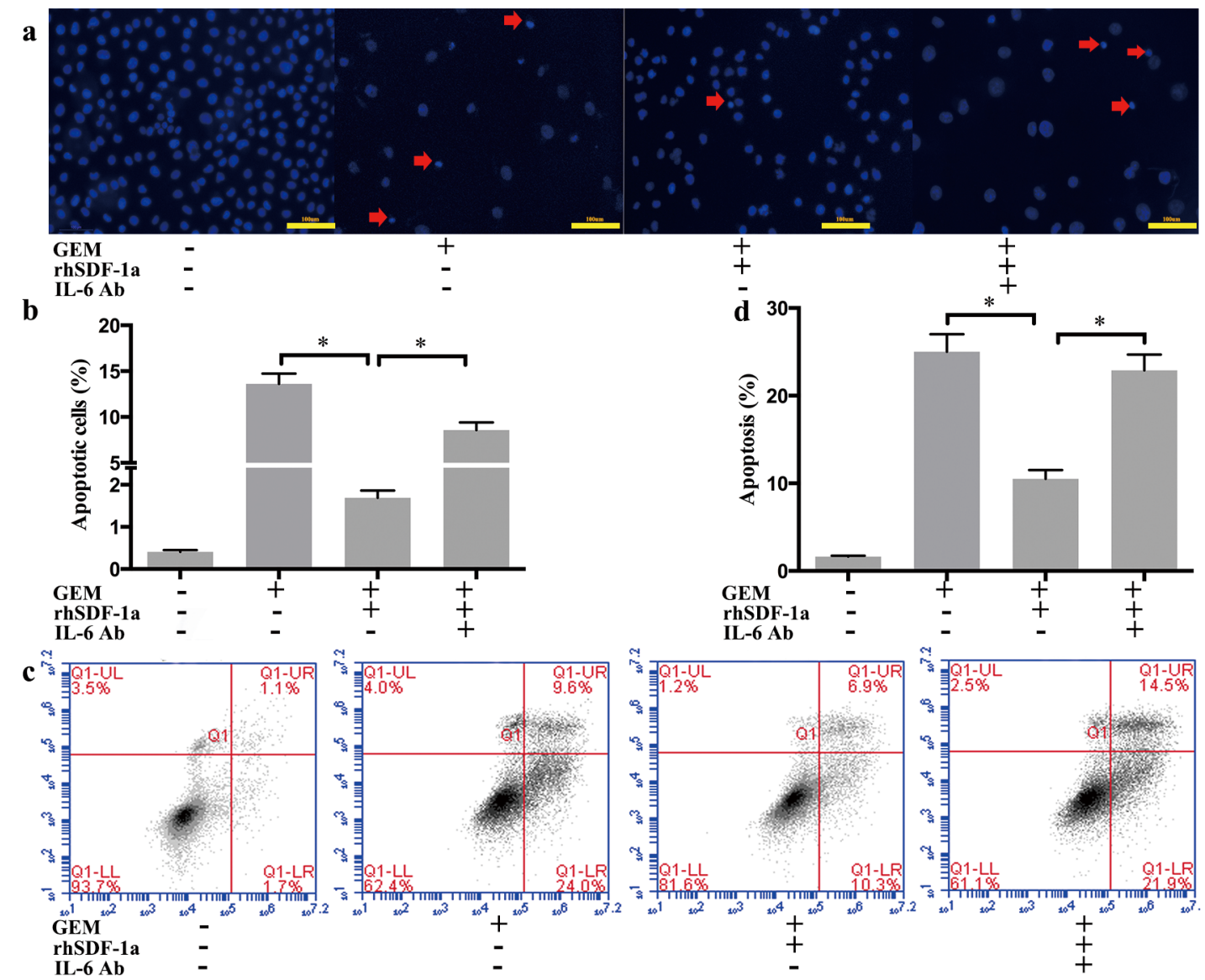

Figure 5: SDF-1 $\alpha$ mediated the effects of PSCs on GEM-induced apoptosis in Panc-1 cells. Panc-1 cells were cultured in serum-free medium containing GEM $(10 \mu \mathrm{M})$, with rhSDF-1 $\alpha(100 \mathrm{ng} / \mathrm{ml})$, IL-6 Ab $(1 \mu \mathrm{g} / \mathrm{ml})$ or the vehicle for $72 \mathrm{~h}$. (a): Apoptotic cells were examined by Hoechst 33342 staining (the arrow indicates the apoptotic cells), and (b) the percentage of apoptotic cells was statistically analyzed. (c): Cells were harvested for flow cytometry analysis of Annexin-V labeling, and (d) the proportion of cells in earlystage apoptosis was statistically analyzed. Bars represent the mean of three independent experiments $\pm \mathrm{SE}$. *, P $<0.05$. 
high levels of SDF-1 $\alpha$, while high CXCR4 expression was typically observed in PCCs. Moreover, distant normal pancreas tissue was negative for both SDF-1 $\alpha$ and CXCR4 staining, and PSCs inactivation by ATRA significantly decreased SDF-1a expression in PSCs. Our results indicated that the SDF- $1 \alpha / \mathrm{CXCR} 4$ axis was activated in PCCs.

Previous studies have shown that PSC-CM could promote the proliferation, migration, invasion and organ-specific metastasis of PCCs through the SDF-1 $\alpha$ / CXCR4 axis [30, 31]. Although the effect of the SDF-1 $\alpha /$ CXCR4 axis on chemoresistance to GEM in PCCs has been reported [32], it remains unclear whether and how the SDF-1 $\alpha /$ CXCR 4 axis mediates the effect of PSCs on GEM chemoresistance. The present study confirmed that
PSCs promoted the chemoresistance of PCCs to GEM, which was at least partially mediated by paracrine SDF$1 \alpha$ signaling. Our findings suggested that blocking the PSC-PCC interaction by inhibiting the SDF-1 $\alpha / C X C R 4$ signaling pathways may be a promising therapeutic strategy for overcoming chemoresistance in pancreatic cancer. Compared with previous studies that focused on PCCs themselves, investigation of the interactions between PSCs or tumor stroma and tumor cells might provide more information about the conditions in vivo and thus be highly useful for studying chemoresistance. In our previous study, we reported that the ECM component laminin increased the chemoresistance of PCCs to GEM [11]. The results provided new insights into the critical role of the tumor microenvironment in chemoresistance a

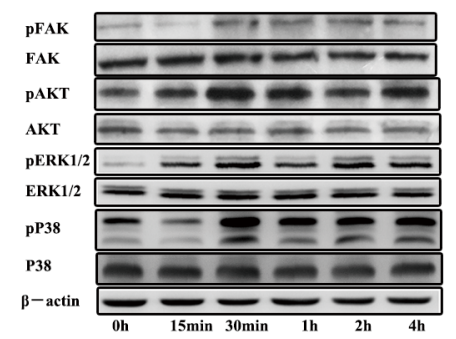

b

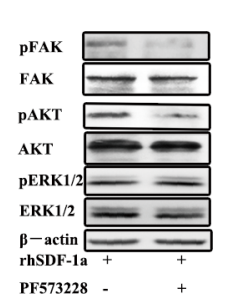

C

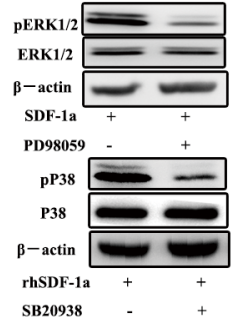

d

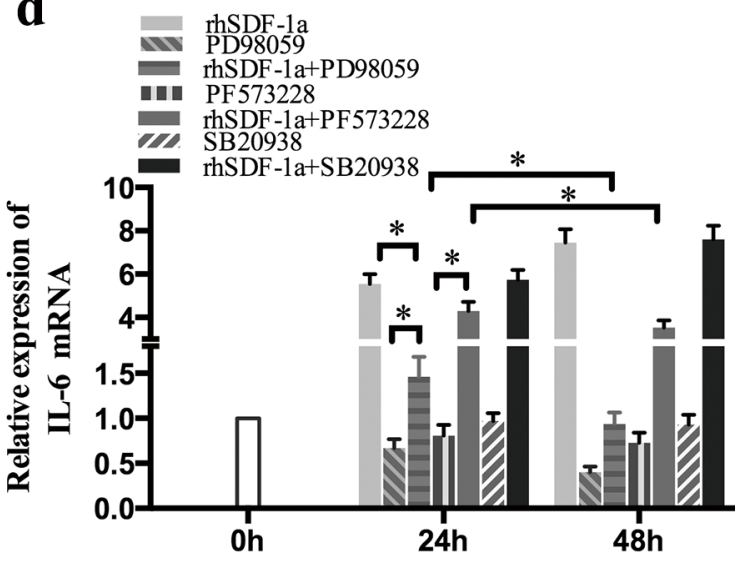

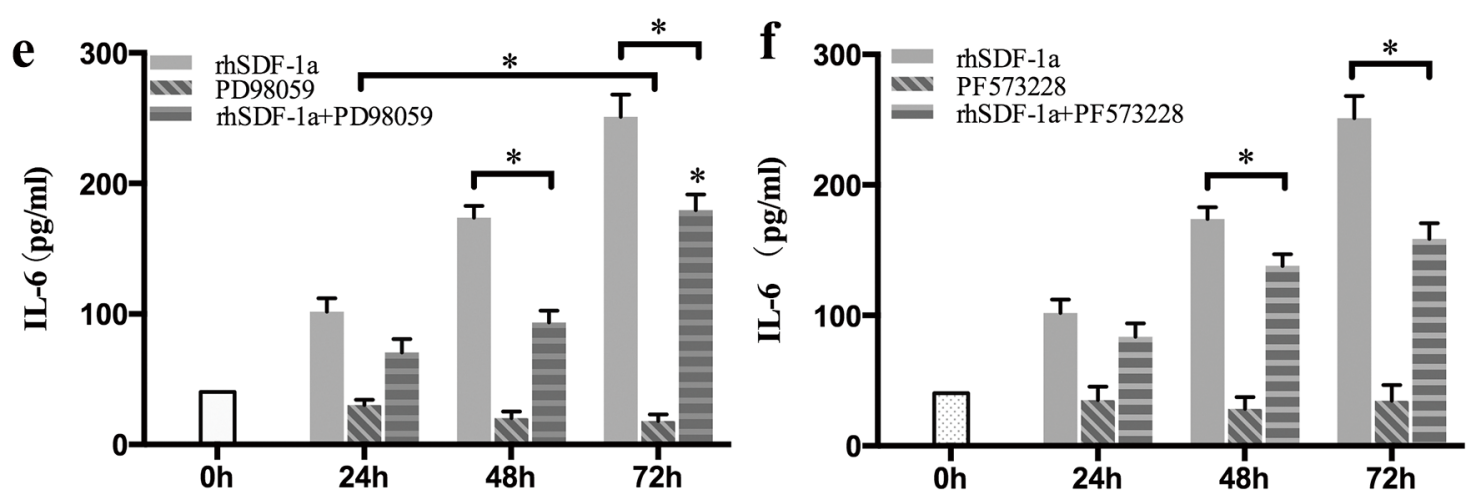

Figure 6: SDF-1a upregulated IL-6 expression in Panc-1 cells through the activation of FAK-AKT and ERK1/2 signaling. (a): Panc-1 cells were treated with rhSDF-1 $\alpha(100 \mathrm{ng} / \mathrm{ml})$ or the vehicle for $15 \mathrm{~min}, 30 \mathrm{~min}, 1 \mathrm{~h}, 2 \mathrm{~h}$ or $4 \mathrm{~h}$. The expression and phosphorylation of FAK, AKT, ERK1/2, and P38 in Panc-1 cells was detected by western blotting. (b): Panc-1 cells were pretreated with PF537228 (FAK inhibitor) or control vehicle for $1 \mathrm{~h}$ and then treated with rhSDF-1 $\alpha$ for an additional 30 min. The expression and phosphorylation of FAK, AKT, and ERK1/2 in Panc-1 cells were examined by western blotting. (c): Panc-1 cells were pretreated with PD98059 (an ERK inhibitor), SB20938 (a P38 inhibitor) or the vehicle for $1 \mathrm{~h}$, followed by treatment with rhSDF-1 $\alpha$ for an additional 30 min. The expression and phosphorylation of ERK1/2 and P38 in Panc-1 cells were detected by western blotting. (d): Panc-1 cells were pretreated with PF537228, PD98059, SB20938 or the vehicle for $1 \mathrm{~h}$, followed by treatment with rhSDF-1 $\alpha$ for an additional $24 \mathrm{~h}, 48 \mathrm{~h}$, or 72 h. IL-6 mRNA expression in Panc-1 cells was tested by RT-qPCR. Panc-1 cells were pretreated with PD98059 (e), PF573228 (f) or vehicle for $1 \mathrm{~h}$, followed by treatment with rhSDF-1a for an additional $24 \mathrm{~h}, 48 \mathrm{~h}$, or $72 \mathrm{~h}$. IL-6 expression in the culture supernatants was tested by ELISA. The bars represent the mean of three independent experiments $\pm \mathrm{SE}$. $*, \mathrm{P}<0.05$ 
Table 1: The clinicopathological data of four patients with surgically resected pancreatic cancer.

\begin{tabular}{|c|c|c|c|c|c|c|}
\hline Number & Gender & Age & Differentiation & Size(cm) & Location & $\begin{array}{c}\text { TNM stage } \\
\text { Grade }\end{array}$ \\
\hline S1 & F & 71 & Moderate & 6 & Body & IIA (T3N0M0) \\
\hline S2 & M & 55 & Moderate & 3 & Tail & IIA (T3N0M0) \\
\hline S3 & F & 57 & Well & 5 & Tail & III (T4N0M0) \\
\hline S4 & F & 80 & Well & 3 & Head & IIB (T3N1M0) \\
\hline
\end{tabular}

and offered a reasonable explanation for the frequently observed discrepancy between in vitro drug sensitivity and the in vivo clinical response in pancreatic cancer.

SDF-1 has been reported to stimulate different types of cells to produce a variety of soluble factors, including IL-6, IL-8, and MMP, upon binding to its specific receptor CXCR4. Moreover, the effects are cell-type specific [33-35] . The present study found that the SDF$1 \alpha /$ CXCR4 axis upregulated IL- 6 in a time- and dosedependent manner in Panc-1 cells. As a multifunctional growth factor, IL-6 was originally discovered in T cells, and it can promote $\mathrm{B}$ cell maturation. In addition to the inflammatory response, IL-6 has also been shown to be associated with various biological behaviors of tumor cells, including growth, survival, metastasis, angiogenesis, epithelial-mesenchymal transformation (EMT) and chemoresistance [36-38]. In vitro and in vivo experiments confirmed that IL-6 could inhibit apoptosis of pancreatic intraepithelial neoplasia (PanIN) cell lines and promote the development of precancerous lesions and pancreatic cancer, which indicated that IL-6 is involved in early stages of pancreatic cancer development [39]. Mitsunaga [22] et al. reported that a high serum IL-6 level was a poor prognostic factor for overall survival in in patients with pancreatic cancer. Moreover, high expression of IL-6 receptor (IL-6R) was confirmed in PCCs and the activation of IL-6R-related pathway in tumor cells was associated with a poor outcome in resected pancreatic ductal adenocarcinoma [40, 41]. Our previous study also showed that IL- 6 could prevent PCCs migration and the EMT [12]. All these results suggest that IL-6-mediated intracellular signaling cascades in tumor cells might play important roles in pancreatic cancer progression. In the present study, we revealed for the first time that exogenous SDF-1 $\alpha$ induced intracellular expression and extracellular secretion of IL-6 in Panc-1 cells, and the protective effects of SDF- $1 \alpha$ on GEM-induced apoptosis in Panc- 1 cells were at least partially mediated by IL-6, indicating that an IL-6 autocrine loop might contribute to SDF- $1 \alpha$-induced GEM chemoresistance in PCCs. The IL-6 autocrine loop in PCCs might be an effective target for blocking SDF-1 $\alpha$-mediated PSC-PCC interactions. Autocrine IL-6 signaling has also been found to promote growth, metastasis and chemoresistance in a variety of tumors, including breast, ovarian and endometrial cancers [40, 42-
44]. It has been reported that IL-6 could protect tumors from chemotherapy-induced apoptosis by regulating the expression of apoptosis-related genes [32, 45]. Whether the SDF- $1 \alpha$-induced IL- 6 autocrine loop regulates the expression of apoptosis-related genes in PCCs needs further investigation.

The SDF- $1 \alpha /$ CXCR 4 biological axis can activate multiple intracellular signaling pathways, including the FAK, AKT, ERK1/2, P38, STAT3, mTOR, and Wnt/ $\beta$ catenin signaling pathways in various cancers $[24,35,46$, 47]. Our results indicated that the FAK-AKT, ERK $1 / 2$ and P38 signaling pathways were all activated by SDF- $1 \alpha$ in PCCs, and the FAK-AKT and ERK1/2 signaling pathways most likely mediated the SDF-1 $\alpha$-induced upregulation of IL-6 in PCCs. Consistent with the present study, our previous findings also demonstrated the critical role of FAK-AKT in the ECM-induced chemoresistance of PCCs, and the combination of selective FAK inhibitors with GEM might be a very promising therapeutic strategy for pancreatic cancer [11]. These results suggested that FAKAKT and ERK1/2 might be critical intracellular signaling pathways in PCCs through mediation of the tumor-stroma interaction. The selective inhibition of these signaling pathways may present a potential therapeutic target for pancreatic cancer.

In conclusion, our results demonstrate that PSCs contribute to the chemoresistance of PCCs to GEM. Moreover, we show for the first time that the effects of PSCs on GEM chemoresistance are mediated through paracrine SDF-1 $\alpha /$ CXCR 4 signaling and, subsequently, the IL-6 autocrine loop in PCCs. Our results also reveal that SDF-1 $\alpha$-induced IL-6 upregulation in PCCs may be partially due to its downstream activation of the intracellular FAK-AKT and ERK1/2 signaling pathways. Our findings indicate that the interaction between PSCs and PCCs plays a critical role in pancreatic cancer chemoresistance, and blocking the PSC-PCC interaction by inhibiting the SDF-1 $\alpha /$ CXCR 4 axis and its downstream signaling pathways may be a promising therapeutic strategy for overcoming chemoresistance in pancreatic cancer. 


\section{MATERIALS AND METHODS}

\section{Cell culture and isolation}

Human PCC lines (MIA PaCa-2, Panc-1, AsPC-1, BxPC-3) were purchased from the American Type Culture Collection (ATCC). The cell lines were maintained in culture as an adherent monolayer in RPMI-1640 or Dulbecco's Modified Eagle's Medium (DMEM) supplemented with $10 \%$ fetal bovine serum (FBS) and 100 $\mathrm{mM}$ each of penicillin and streptomycin. Cells were grown at $37^{\circ} \mathrm{C}$ with $5 \% \mathrm{CO} 2$ in a humidified atmosphere.

Human PSCs were isolated from four surgically resected pancreatic cancer tissues as previously reported (Bachem et al, 1998), and the clinicopathological data of the four patients are listed in Table 1. Briefly, tumor tissues were cut into $1-\mathrm{mm} 3$ cubic blocks with a sterile sharp blade and seeded in 6-well culture plates with 4 to 6 pieces per well. The explants were kept in DMEM/F-12 (1:1) culture medium containing 10\% FBS with antibiotics, and the medium was changed every 2 days. After cells grew out from the tissue explants and reached $90 \%$ confluence, the cells were digested with $0.05 \%$ trypsin and cultured in DMEM/F-12 with $10 \%$ FBS at $37^{\circ} \mathrm{C}$ and $5 \% \mathrm{CO}_{2}$. PSCs from passages 3 to 7 were identified by immunofluorescence staining for $\alpha$-SMA (Dako, Carpenteria, CA, USA) and vimentin (Abcam, Cambridge, MA, USA) and used for further study. All human samples were obtained in accordance with the policies and practices of the Institutional Review Board of Peking Union Medical College Hospital.

\section{Preparation of conditioned medium}

Primary PSCs $\left(1 \times 10^{6}\right.$ cells $)$ were plated in T25 flasks containing FBS-free DMEM/F12 (1:1). After $24 \mathrm{~h}$, the PSC-conditioned medium (PSC-CM) was harvested, centrifuged at $1,200 \mathrm{rpm}$ for $5 \mathrm{~min}$, and stored at $-80^{\circ} \mathrm{C}$ until use. For the indirect co-culture with PCC, PSC$\mathrm{CM}$ was added to the tumor cells, and the medium was changed every day for 3 days.

\section{Reagents}

Gemcitabine (GEM) was purchased from Eli Lilly (Indianapolis, IN, USA). AMD3100, MTT, Hoechst 33342, PD98059 (an ERK inhibitor), PF573228 (a FAK inhibitor), SB20938 (a P38 inhibitor) were all supplied by Sigma-Aldrich (St. Louis, MO, USA). Recombinant human SDF-1 $\alpha$ (rhSDF-1 $\alpha$ ), the anti-IL-6 mouse monoclonal antibody $(\mathrm{mAb})$ and the IL-6 ELISA kit were purchased from R\&D Systems (Minneapolis, MN, USA). The anti- $\alpha$ SMA mouse mAb was from Dako. The anti- vimentin and anti-SDF- $1 \alpha$ mouse mAbs, the anti-CXCR4 rabbit polyclonal antibody and the SDF- $1 \alpha$ neutralizing antibody (SDF-1 $\alpha \mathrm{Ab}$ ) were from Abcam. Rabbit mAbs against pAKT (Ser473), pP38 (Thr180/Tyr182), ERK1/2, pERK1/2 (Thr202/Tyr204) and pFAK (Tyr397) were from Cell Signaling Technologies (Beverly, MA, USA). The mouse $\mathrm{mAb}$ against FAK, rabbit $\mathrm{mAbs}$ against $\mathrm{AKT}$ and and $\beta$-actin, the rabbit polyclonal antibody against P38, and the secondary horseradish peroxidase-conjugated antirabbit and anti-mouse antibodies were all purchased from Santa Cruz Biotechnology (Santa Cruz, CA, USA).

\section{Evaluation of gene expression by real-time PCR (RT-qPCR)}

Total RNA was extracted from PCC and PSC using TRIzol reagent (Invitrogen, Carlsbad, CA, USA). The complementary DNA was synthesized using the High Capacity cDNA Reverse Transcription Kit (Applied Biosystems, Foster City, CA, USA) according to the manufacturer's protocol. RT-qPCR was performed as described by the manufacturer using the Power SYBR green PCR master mix (Applied Biosystems). The sequences of the primers used are listed in Table 2. The transcript level for each specific gene was normalized to the level of $\beta$-actin mRNA and was calculated using the comparative threshold cycle $(\mathrm{Ct})$ method $\left(2^{-\Delta \Delta \mathrm{Ct}}\right)$.

\section{Immunohistochemistry}

Paraffin-embedded tissue sections were deparaffinized, rehydrated, rinsed, immersed in 10 $\mathrm{mM}$ sodium citrate, heated for 20 minutes, and cooled for 20 minutes. The sections were incubated with a primary antibody against $\alpha$-SMA (1:50 dilution), SDF$1 \alpha\left(1: 100\right.$ dilution), or CXCR4 (1:100 dilution) at $4^{\circ} \mathrm{C}$ overnight followed by incubation with the secondary antibody. The immunostaining was developed with 3,3'-diaminobenzidine (DAB). Appropriate positive and negative controls were run.

\section{Western blot analysis}

Cells were processed for protein extraction and western blotting using standard procedures. Briefly, the cells were washed twice with phosphate-buffered saline (PBS) and scraped into RIPA lysis buffer containing protease and phosphatase inhibitors. The cell lysates were passed through a needle syringe to facilitate the disruption of the cell membranes and were centrifuged at $14000 \mathrm{rpm}$ for $10 \mathrm{~min}$ at $4^{\circ} \mathrm{C}$, and the supernatants were collected. Proteins $(15-30 \mu \mathrm{g})$ were resolved by electrophoresis on 10-15\% SDS-PAGE gels, transferred onto polyvinylidene difluoride membranes and subjected to a standard 
Table 2: List of primers

\begin{tabular}{|l|l|l|l|l|}
\hline Name & Forward & Reverse & Production size & Ta $^{\text {Opt }}{ }^{\circ} \mathbf{C}^{-}$ \\
\hline$\beta$-actin & GCCAACACAGTGCTGTCTGG & GCTCAGGAGGAGCAATGATCTTG & $100 \mathrm{bp}$ & 50.4 \\
\hline SDF-1 $\alpha$ & TCCCAGCTATTCCTACTCTCTC & CCAGCAATCACCCTCTTC & $114 \mathrm{bp}$ & 52.6 \\
\hline CXCR4 & GAAATCATCAAGCAAGGGTG & GCTCCAAGGAAAGCATAGAG & $119 \mathrm{bp}$ & 56.0 \\
\hline IL-6 & GTCCAGTTGCCTTCTCCC & GCCTCTTTGCTGCTTTCA & $223 \mathrm{bp}$ & 53.7 \\
\hline IL-8 & TCCAAACCTTTCCACCCC & CACAACCCTCTGCACCCA & $147 \mathrm{bp}$ & 51.8 \\
\hline
\end{tabular}

immunodetection procedure using specific antibodies against ERK1/2, pERK1/2, AKT, pAKT, FAK, pFAK, P38, pP38 and $\beta$-actin (1:1000 dilution). All secondary antibodies were used at a 1:5000 dilution. The blots were processed with the ECL Plus Western Blotting detection kit (Pierce Biotechnology, Rockford, IL, USA), and the signal was detected using an LAS-3000 image analyzer (Fuji Photo Film Co., Tokyo, Japan).

\section{Cell viability assay}

Panc-1 cells were seeded in 96-well plates at a density of 4000 cells per well and allowed to settle for 24 $\mathrm{h}$, followed by treatment with GEM $(10 \mu \mathrm{M})$ under serumfree conditions in the presence or absence of various doses of PSC-CM (20\%, 40\%, 60\%, 80\%, and 100\%) and SDF$1 \alpha \mathrm{Ab}$. After $24 \mathrm{~h}, 48 \mathrm{~h}$, or $72 \mathrm{~h}$ of treatment, cell growth was determined using the MTT cell proliferation assay. Viability was calculated as percent $(\%)=(\mathrm{A} / \mathrm{B}) \times 100$, where $\mathrm{A}$ and $\mathrm{B}$ were the absorbance of the experimental and control groups, respectively.

\section{Analysis of apoptosis based on nuclear morphology}

Distilled slides were placed onto the surface of 6-well plates. Panc-1 cells $\left(1.6 \times 10^{5}\right)$ were seeded onto the slides, allowed to settle for $24 \mathrm{~h}$ in serum-free medium, and then cultured with fresh medium containing GEM $(10 \mu \mathrm{M})$ in the presence or absence of PSC-CM, rhSDF-1 $\alpha(100 \mathrm{ng} /$ $\mathrm{ml})$, SDF-1 $\alpha \mathrm{Ab}(100 \mathrm{ng} / \mathrm{ml})$ and/or IL-6 Ab $(1 \mu \mathrm{g} / \mathrm{ml})$ for $72 \mathrm{~h}$. After treatment, the slides were washed with PBS, and the cells were fixed with 4\% paraformaldehyde for 20 min. The slides were washed again with PBS, and $0.1 \mathrm{ml}$ of Hoechst $33342(1 \mu \mathrm{g} / \mathrm{ml})$ was added to each slide. The slides were incubated in the dark at room temperature for 15 min and then washed three times with PBS. The cells were examined using a fluorescence microscope (Motic, Germany) and photographed. Apoptosis was evaluated based on nuclear condensation.

\section{Flow cytometric assay of apoptosis}

Panc-1 cells were treated as described in Section 2.8. The cells were collected, washed twice in ice-cold
PBS, resuspended in $1 \times$ binding buffer, and then incubated with FITC-conjugated annexin V and PI (BD Pharmingen, Franklin Lakes, NJ, USA) for $15 \mathrm{~min}$ at room temperature in the dark. The samples were analyzed by FACS using Cell Quest Research Software (BD Pharmingen).

\section{Enzyme-linked immunosorbent assay}

Panc- 1 cells $(1.6 \times 105)$ were seeded in 6-well plates and cultured in serum-free medium for $24 \mathrm{~h}$. The cells were then cultured with fresh medium for $24 \mathrm{~h}, 48 \mathrm{~h}$ or 72 h. The culture supernatants were collected, centrifuged at 1500 r.p.m for $5 \mathrm{~min}$ to remove particulate material, and frozen at $-80^{\circ} \mathrm{C}$ until use. The cell number in each well was counted. IL-6 was measured using an IL-6 ELISA Kit according to the manufacturer's instructions. The IL-6 concentration was normalized to 1 x105 cells in each sample.

\section{Statistical analysis}

Each experiment was performed at least three times, and all the values were expressed as the mean $\pm \mathrm{SE}$. The differences between the groups were compared using student's t-tests. The level of significance was defined as $P \leq 0.05$ (two tailed).

\section{ACKNOWLEDGEMENT}

This work was supported by the National Natural Science Foundation, China (Project No. 81150027).

\section{ABBREVIATIONS}

CXC chemokine receptor 4 (CXCR4); Extracellular matrix (ECM); Epithelial-mesenchymal transformation (EMT); Gemcitabine (GEM); IL-6 receptor (IL-6R); Matrix metallopeptidases (MMP); Pancreatic cancer cell (PCC); Pancreatic stellate cell (PSC); PSC-conditioned medium (PSC-CM); Stromal cell-derived factor-1 (SDF$1)$. 


\section{CONFLICT OF INTEREST}

None of the authors have any conflict of interest to disclose regarding this study.

\section{REFERENCES}

1. Guo X, Cui Z. Current diagnosis and treatment of pancreatic cancer in China. Pancreas. 2005; 31:13-22.

2. Wang L, Yang GH, Li H, Lu XH. Pancreatic cancer mortality in China (1991-2000). World J Gastroenterol. 2003;9:1819-23.

3. Siegel R, Naishadham D, Jemal A. Cancer statistics, 2012. CA Cancer J Clin. 2012; 62:10-29.

4. Neoptolemos JP, Stocken DD, Friess H, Bassi C, Dunn JA, Hickey H, Beger H, Fernandez-Cruz L, Dervenis C, Lacaine F, Falconi M, Pederzoli P, Pap A, et al. European Study Group for Pancreatic Cancer.A randomized trial of chemoradiotherapy and chemotherapy after resection of pancreatic cancer. N Engl J Med. 2004; 350:1200-210.

5. O'Reilly EM, Abou-Alfa GK. Cytotoxic therapy for advanced pancreatic adenocarcinoma.SeminOncol 2007;34:347-353.

6. Apte MV, Park S, Phillips PA, Santucci N, Goldstein D, Kumar RK, Ramm GA, Buchler M, Friess H, McCarroll JA, Keogh G, Merrett N, Pirola R, et al. Desmoplastic reaction in pancreatic cancer: role of pancreatic stellate cells. Pancreas. 2004;29:179-187.

7. Luttenberger T, Schmid-Kotsas A, Menke A, Siech M, Beger H, Adler G, Grünert A, Bachem MG, Platelet-derived growth factors stimulate proliferation andextracellular matrix synthesis of pancreatic stellate cells: implications inpathogenesis of pancreas fibrosis. Lab Invest. 2000; 80:47-55.

8. Vonlaufen A, Phillips PA, Xu Z, Goldstein D, Pirola RC, Wilson JS, Apte MV. Pancreatic stellate cells and pancreatic cancer cells: an unholy alliance. Cancer Res 2008; 68:7707-7710.

9. Vonlaufen A, Joshi S, Qu C, Phillips PA, Xu Z, Parker NR, Toi CS, Pirola RC, Wilson JS, Goldstein D, Apte MV. Pancreatic stellate cells: partners in crime with pancreatic cancer cells. Cancer Res. 2008; 68:2085-2093.

10. Trimboli AJ, Cantemir-Stone CZ, Li F, Wallace JA, Merchant A, Creasap N, Thompson JC, Caserta E, Wang H, Chong JL, Naidu S, Wei G, Sharma SM, et al. Pten in stromal fibroblasts suppresses mammary epithelial tumours. Nature. 2009; 461:1084-1091.

11. Huanwen W, Zhiyong L, Xiaohua S, Xinyu R, Kai W, Tonghua L. Intrinsic chemoresistance to gemcitabine is associated with constitutive and laminin-induced phosphorylation of FAK in pancreatic cancer cell lines. Mol Cancer. 2009; 8:125.

12. Guan J, Zhang H, Wen Z, Gu Y, Cheng Y, Sun Y, Zhang T, Jia C, Lu Z, Chen J. Retinoic acid inhibits pancreatic cancer cell migration and EMT through the downregulation of IL-6 in cancer associated fibroblast cells. Cancer Lett. 2014;345:132-139.

13. Tashiro K, Tada H, Heilker R, Shirozu M, Nakano T, Honjo T. Signal sequence trap: a cloning strategy for secreted proteins and type I membrane proteins. Science. 1993; 261:600-603.

14. Davis DA, Singer KE, De La Luz Sierra M, Narazaki M, Yang F, Fales HM, et al. Identification of carboxypeptidase $\mathrm{N}$ as an enzyme responsible for $\mathrm{C}$-terminal cleavage of stromal cell-derived factor-1alpha in the circulation. Blood. 2005; 105:4561-4568.

15. Davis DA, Singer KE, De La Luz Sierra M, Narazaki M, Yang F, Fales HM, Yarchoan R, Tosato G. Overactivation of the TGF- $\beta$ pathway confers a mesenchymal-like phenotype and CXCR4-dependent migratory properties to liver tumor cells. Hepatology 2013; 58:2032-2044.

16. Conley-LaComb MK, Saliganan A, Kandagatla P, Chen YQ, Cher ML, Chinni SR. PTEN loss mediated Akt activation promotes prostate tumor growth and metastasis via CXCL12/CXCR4 signaling. Mol Cancer. 2013;12:85.

17. Choi YH1, Burdick MD, Strieter BA, Mehrad B, Strieter RM. CXCR4, but not CXCR7, discriminates metastatic behavior in non-small cell lung cancer cells. Mol Cancer Res. 2014;12:38-47.

18. Lee BC, Lee TH, Avraham S, Avraham HK. Involvement of the chemokine receptor CXCR4 and its ligand stromal cell-derived factor 1alpha in breast cancer cell migration through human brain microvascular endothelial cells. Mol Cancer Res. 2004; 2:327-338.

19. Roy I, Zimmerman NP, Mackinnon AC, Tsai S, Evans DB, Dwinell MB. CXCL12 Chemokine Expression Suppresses Human Pancreatic Cancer Growth and Metastasis. PLoS One. 2014;9:e90400.

20. Bachem MG1, Schneider E, Gross H, Weidenbach H, Schmid RM, Menke A, Siech M, Beger H, Grünert A, Adler G. Identification, culture, and characterization of pancreatic stellate cells in rats and humans. Gastroenterology. 1998;115:421-432.

21. Heckmann D, Maier P, Laufs S, Li L, Sleeman JP, Trunk MJ, Leupold JH, Wenz F, Zeller WJ, Fruehauf S, Allgayer H. The disparate twins: a comparative study of CXCR4 and CXCR7 in SDF-1 $\alpha$-induced gene expression, invasion and chemosensitivity of colon cancer. Clin Cancer Res. 2014;20:604-616.

22. Mitsunaga S, Ikeda M, Shimizu S, Ohno I, Furuse J, Inagaki M, Higashi S, Kato H, Terao K, Ochiai A. Serum levels of IL- 6 and IL- $1 \beta$ can predict the efficacy of gemcitabine in patients with advanced pancreatic cancer. Br J Cancer. 2013;108:2063-2069.

23. Meng H, Zhao Y, Dong J, Xue M, Lin YS, Ji Z, Mai WX, Zhang $\mathrm{H}$, Chang $\mathrm{CH}$, Brinker CJ, Zink JI. Two-wave nanotherapy to target the stroma and optimize gemcitabine delivery to a human pancreatic cancer model in mice. ACS 
Nano. 2013;7:10048-10065

24. Weekes CD, Song D, Arcaroli J, Wilson LA, RubioViqueira B, Cusatis G, Garrett-Mayer E, Messersmith WA, Winn RA, Hidalgo M. Stromal cell-derived factor $1 \alpha$ mediates resistance to $\mathrm{mTOR}$-directed therapy in pancreatic cancer. Neoplasia. 2012;14: 690-701.

25. Mantoni TS, Lunardi S, Al-Assar O, Masamune A, Brunner TB. Pancreatic stellate cells radioprotect pancreatic cancer cells through $\beta 1$-integrin signaling. Cancer Res. 2011;71:3453-3458

26. Ottaiano A, Franco R, Aiello Talamanca A, Liguori G, Tatangelo F, Delrio P, Nasti G, Barletta E, Facchini G, Daniele B, Di Blasi A, Napolitano M, Ieranò C, et al. Overexpression of both $\mathrm{CXC}$ chemokine receptor 4 and vascular endothelial growth factor proteins predicts early distant relapse in stage II-III colorectal cancer patients. Clin Cancer Res. 2006;12: 2795-2803.

27. Popple A, Durrant LG, Spendlove I, Rolland P, Scott IV, Deen S, Ramage JM. The chemokine, CXCL12, is an independent predictor of poor survival in ovariancancer. $\mathrm{Br}$ J Cancer. 2012;106:1306-1313.

28. Ramos EA, Camargo AA, Braun K, Slowik R, Cavalli IJ, Ribeiro EM, PedrosaFde O, de Souza EM, Costa FF, Klassen G. Simultaneous CXCL12 and ESR1 CpG island hypermethylation correlates with poor prognosis in sporadic breast cancer. BMC Cancer. 2010; 10:23.

29. Shibata W, Ariyama H, Westphalen CB, Worthley DL, Muthupalani S, Asfaha S, Dubeykovskaya Z, Quante M, Fox JG, Wang TC. Stromal cell-derived factor-1 overexpression induces gastric dysplasia through expansion of stromal myofibroblasts and epithelial progenitors. Gut. 2013; 62:192-200.

30. Gao Z, Wang X, Wu K, Zhao Y, Hu G. Pancreatic stellate cells increase the invasion of human pancreatic cancer cells through the stromal cell-derived factor-1/CXCR4 axis. Pancreatology. 2010;10:186-193.

31. Zhong W, Chen W, Zhang D, Sun J, Li Y, Zhang J, Gao Y, Zhou W, Li S. CXCL12/CXCR4 axis plays pivotal roles in the organ-specific metastasis of pancreatic adenocarcinoma: A clinical study. ExpTher Med. 2012;4:363-369.

32. Singh S, Srivastava SK, Bhardwaj A, Owen LB, Singh AP,. CXCL12-CXCR4 signalling axis confers gemcitabine resistance to pancreatic cancer cells: a novel target for therapy. Br J Cancer. 2010;103:1671-1679.

33. Lin TJ, Issekutz TB, Marshall JS. SDF-1 induces IL-8 production andtransendothelial migration of human cord blood-derived mast cells. Int Arch Allergy Immunol. 2001; 124:142-145.

34. Uchida D, Onoue T, Kuribayashi N, Tomizuka Y, Tamatani T, Nagai H, Miyamoto Y. Blockade of CXCR4 in oral squamous cell carcinoma inhibits lymph node metastases. Eur J Cancer. 2011;47:452-459.

35. Pan F, Ma S, Cao W, Liu H, Chen F,, Chen X, Shi R. SDF$1 \alpha$ upregulation of MMP-2 is mediated by p38 MAPK signaling in pancreatic cancer cell lines. Mol Biol Rep. 2013; 40:4139-4146.

36. Yamada D, Kobayashi S, Wada H, Kawamoto K, Marubashi S, Eguchi H, Ishii H, Nagano H, Doki Y, Mori M. Role of crosstalk between interleukin-6 and transforming growth factor-beta 1 in epithelial-mesenchymal transition andchemoresistance in biliary tract cancer. Eur J Cancer. 2013;49: 1725-1740.

37. Wang Y, Niu XL, Qu Y, Wu J, Zhu YQ, Sun WJ,,Li LZ. Autocrine production of interleukin-6 confers cisplatin and paclitaxel resistance in ovarian cancer cells. Cancer Lett. 2010; 295:110-123.

38. Miyamoto Y, Hosotani R, Doi R, Wada M, Ida J, Tsuji S, Kawaguchi M, Nakajima S, Kobayashi H, Masui T, Imamura M. Interleukin-6 inhibits radiation induced apoptosis in pancreatic cancer cells. Anticancer Res. 2001; 21:2449-2456.

39. Zhang Y, Yan W, Collins MA, Bednar F, Rakshit S, Zetter BR, Stanger BZ, Chung I, Rhim AD, di Magliano MP. Interleukin-6 is required for pancreatic cancer progression by promoting MAPK signaling activation and oxidative stress resistance. Cancer Res. 2013;73: 6359-6374.

40. Block KM, Hanke NT, Maine EA, Baker AF. IL-6 stimulates STAT3 and Pim-1 kinase in pancreatic cancer cell lines. Pancreas. 2012:41:773-781.

41. Denley SM, Jamieson NB, McCall P, Oien KA, Morton JP, Carter CR, Edwards J, McKay CJ. Activation of the IL$6 \mathrm{R} / \mathrm{Jak} /$ stat pathway is associated with a poor outcome in resected pancreatic ductal adenocarcinoma. J Gastrointest Surg. 2013;17:887-898.

42. Hartman ZC, Poage GM, den Hollander P, Tsimelzon A, Hill J, Panupinthu N, Zhang Y, Mazumdar A, Hilsenbeck SG, Mills GB, Brown PH. Growth of triple-negativebreast cancer cells relies upon coordinate autocrine expression of theproinflammatory cytokines IL-6 and IL-8. Cancer Res. 2013; 73:3470-3480.

43. Korkaya H, Kim GI, Davis A, Malik F, Henry NL, Ithimakin S, Quraishi AA, Tawakkol N, D’Angelo R, Paulson AK, Chung S, Luther T, Paholak HJ, et al. Activation of an IL6 inflammatory loop mediates trastuzumab resistance in HER 2+ breast cancer by expanding the cancer stem cell population. Mol Cell. 2012;47:570-584.

44. Ren C, Cheng X, Lu B, Yang G. Activation of interleukin-6/ signal transducerand activator of transcription 3 by human papillomavirus early proteins 6 inducesfibroblast senescence to promote cervical tumourigenesis through autocrineandparacrine pathways in tumour microenvironment. Eur J Cancer. 2013;49:3889-3899.

45. Cohen S, Bruchim I, Graiver D, Evron Z, Oron-Karni V, Pasmanik-Chor M, Eitan R, Bernheim J, Levavi H, Fishman A, Flescher E. Platinum-resistance in ovarian cancer cells is mediated by IL- 6 secretion via the increased expression of its target cIAP-2. J Mol Med (Berl). 2013;91:357-368.

46. Gao H, Priebe W, Glod J, Banerjee D. Activation of 
signal transducers and activators of transcription 3 and focal adhesion kinase by stromal cell-derived factor 1 is required for migration of human mesenchymal stem cells in response to tumor cell-conditioned medium. Stem Cells. 2008;27:857-865.

47. Hu TH, Yao Y, Yu S, Han LL, Wang WJ, Guo H, Tian T, Ruan ZP, Kang XM, Wang J, Nan KJ, Wang SH. SDF-1/ CXCR4 promotes epithelial-mesenchymal transition and progression of colorectal cancer by activation of the Wnt/ $\beta$ catenin signaling pathway. Cancer Lett. 2014;354:417-426. 